\title{
Evaluation of fibrosis in cirrhotic elderly patients with HCC
}

\author{
A Pesce*, MA Trovato, A Branca, R Scilletta, TR Portale, S Puleo \\ From XXIII Annual Meeting of the Italian Society of Geriatric Surgery \\ Lecce, Italy. 2-4 December 2010
}

\section{Background}

Hepatocellular carcinoma ( $\mathrm{HCC})$ is usually associated with liver cirrhosis and is the principal cause of death among patients with cirrhosis [1]. Apart from liver transplantation that may cure both conditions, treatment of HCC and cirrhosis is complex because of the need to be oncologically radical but simultaneously conservative. Hepatectomy is considered an invasive approach and has a marginal role in the treatment of HCC $[2,3]$. The value of hepatic fibrosis is considered a predictive factor of outcome in patients with HCC undergoing liver resection [4].

\section{Materials and methods}

A retrospective analysis of 77 cirrhotic patients, 42 of them with hepatocellular carcinoma, observed from 2008 to 2010 was performed. The mean age was 65.2 years old with 46 men and 31 women. As regards cirrhosis etiology, 51 patients presented cirrhosis HCVrelated, 9 HBV-related, 3 alcohol-related, 2 HBV-HDV co-infections and 12 other etiology. Liver function was assessed according to the Child-Pugh classification: 60 patients were in Child A, 13 in Child B and 4 in Child C. In all patients liver stiffness measurement (LSM) was performed using transient elastography (Fibroscan ${ }^{\circledR}$ ). Forty patients were over 65 years old, thirty-seven under 65 ys.

\section{Results}

The mean value of liver stiffness was $27.9 \mathrm{kPa}$ (F4). In the group of elderly patients the mean value of liver stiffness was $25.2 \mathrm{kPa}$ versus $31.2 \mathrm{kPa}$ of the group of patients under 65 ys. In the elderly group 37 patients were in Child A, 5 in Child B and one in Child C. In the other group 22 patients were in Child A, 8 in Child $\mathrm{B}$ and 3 in Child $\mathrm{C}$.

\section{Conclusions}

These results confirm that the severity of liver fibrosis is directly associated with liver function (Child class) and not with the age of patients. Pre-operative liver stiffness measurement in cirrhotic elderly patients with HCC and Child class A could help us in the evaluation of surgical risk in order to reduce post-operative morbidity and mortality.

Published: 24 August 2011

\section{References}

1. Fattovich G, Giustina G, Degos F, et al: Morbidity and mortality in compensated cirrhosis type C: a retrospective follow-up study of 384 patients. Gastroenterology 1997, 112(2):463-472.

2. Bruix J, Llovet JM: Prognostic prediction and treatment strategy in hepatocellular carcinoma. Hepatology 2002, 35(3):519-524.

3. Llovet JM, Fuster J, Bruix J: Barcelona-Clinic Liver Cancer Group. The Barcelona approach: diagnosis, staging, and treatment of hepatocellular carcinoma. Liver Transpl 2004, 10((2) Suppl (1)):S115-S120.

4. Vauthey JN, Dixon E, Abdalla E, Helton WS, Pawlik TM, Taouly B, Brouquet A, Adam RB: Pretreatment assessment of hepatocellular carcinoma: expert consensus statement. HPBA 2010, 12:289-299.

doi:10.1186/1471-2318-11-S1-A47

Cite this article as: Pesce et al:: Evaluation of fibrosis in cirrhotic elderly patients with HCC. BMC Geriatrics 2011 11(Suppl 1):A47.

\footnotetext{
* Correspondence: nino.fish@hotmail.it

Department of General Surgery, University of Catania, AOU Policlinico-

Vittorio Emanuele, Catania, Italy
} 